This item was submitted to Loughborough's Research Repository by the author.

Items in Figshare are protected by copyright, with all rights reserved, unless otherwise indicated.

\title{
Body mapping of sweating patterns in male athletes in mild exercise-induced hyperthermia
}

PLEASE CITE THE PUBLISHED VERSION

http://dx.doi.org/10.1007/s00421-010-1744-8

PUBLISHER

(C) Springer Verlag

VERSION

AM (Accepted Manuscript)

LICENCE

CC BY-NC-ND 4.0

\section{REPOSITORY RECORD}

Smith, Caroline J., and George Havenith. 2019. "Body Mapping of Sweating Patterns in Male Athletes in Mild Exercise-induced Hyperthermia”. figshare. https://hdl.handle.net/2134/9288. 
This item was submitted to Loughborough's Institutional Repository (https://dspace.lboro.ac.uk/) by the author and is made available under the following Creative Commons Licence conditions.

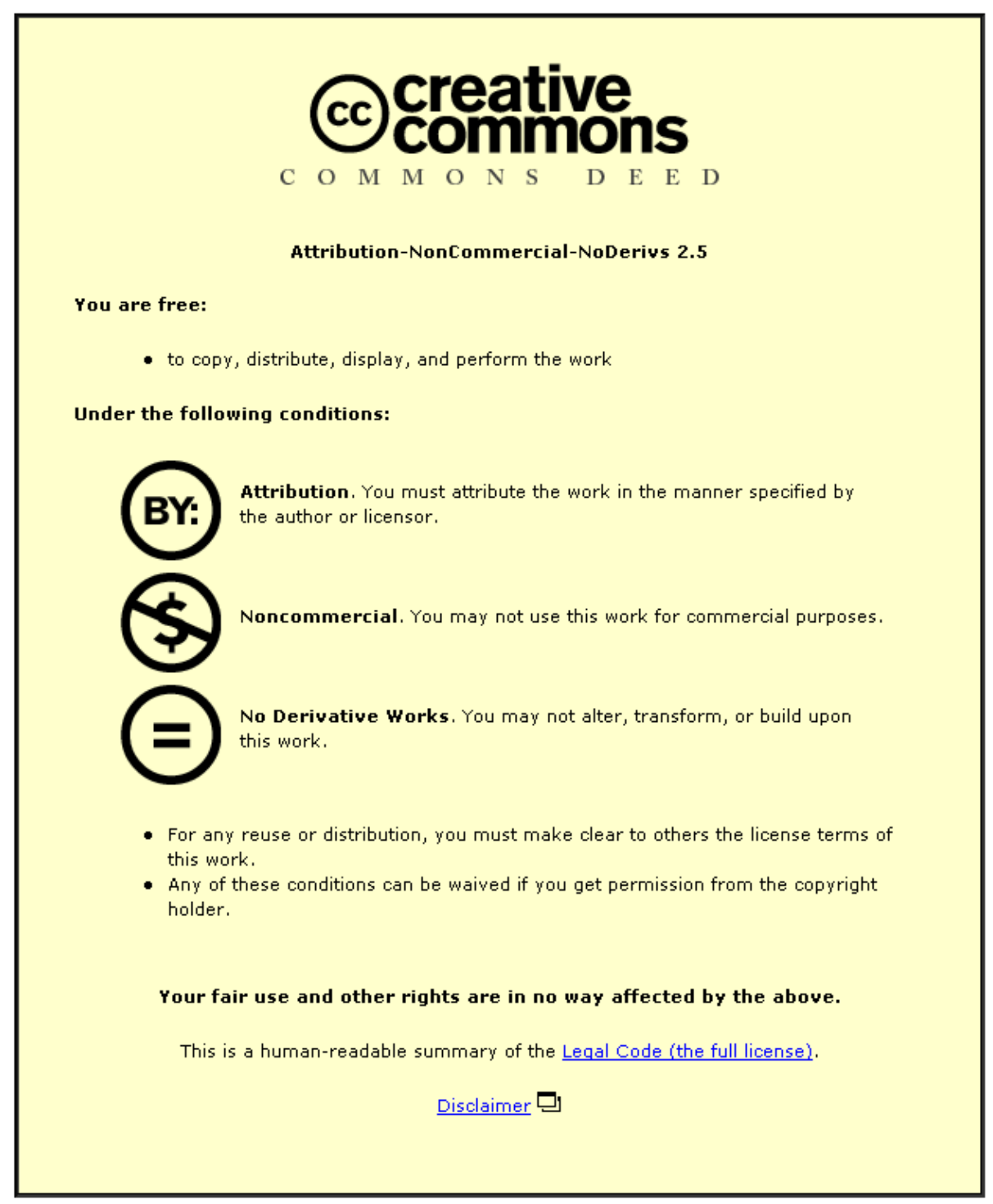

For the full text of this licence, please go to: http://creativecommons.org/licenses/by-nc-nd/2.5/ 


\section{Body Mapping of Sweating Patterns in Male Athletes in Mild Exercise}

\section{Induced Hyperthermia}

Caroline J. Smith and George Havenith

Environmental Ergonomics Research Centre, Loughborough University, UK

Address for correspondence: George Havenith, Loughborough Design School, Environmental Ergonomics Research Centre, Loughborough University, Loughborough, Leicestershire,

LE11 3TU. UK.

Phone: +44 (0)1509 223031

Fax: +44 (0)1509 223014

Email: G.Havenith@lboro.ac.uk

Version 01-11-2010

Please note: more background information is provided in the uploaded files for 'Electronic supplementary Material' which after publication can be downloaded from the Journal's website. 


\section{Abstract}

Regional variation in sweating over the body is widely recognised. However, most studies only measured a limited number of regions, with the use of differing thermal states across studies making a good meta-analysis to obtain a whole body map problematic. A study was therefore conducted to investigate regional sweat rates (RSR) and distributions over the whole body in male athletes. A modified absorbent technique was used to collect sweat at two exercise intensities (55\% (I1) and 75\% (I2) $\left.\dot{\mathrm{V}} \mathrm{O}_{2 \text { max }}\right)$ in moderately warm conditions $\left(25^{\circ} \mathrm{C}, 50 \% \mathrm{rh}, 2 \mathrm{~m} . \mathrm{s}^{-1}\right.$ air velocity). At I1 and I2, highest sweat rates were observed on the central (upper and mid) and lower back, with values as high as 1197,1148 , and 856 g.m $\mathrm{m}^{-2} \cdot \mathrm{h}^{-1}$ respectively at I2. Lowest values were observed on the fingers, thumbs, and palms, with values of 144,254 , and 119 g. $\mathrm{m}^{-2} \cdot \mathrm{h}^{-1}$ respectively at I2. Sweat mapping of the head demonstrated high sweat rates on the forehead $\left(1710 \mathrm{~g} \cdot \mathrm{m}^{-2} \cdot \mathrm{h}^{-1}\right.$ at I2) compared to low values on the chin (302 g. $\mathrm{m}^{-2} \cdot \mathrm{h}^{-1}$ at I2) and cheeks (279 g. $\mathrm{m}^{-2} \cdot \mathrm{h}^{-1}$ at I2). Sweat rate increased significantly in all regions from the low to high exercise intensity, with exception to the feet and ankles. No significant correlation was present between RSR and regional skin temperature $\left(\mathrm{T}_{\mathrm{sk}}\right)$, nor did RSR correspond to known patterns of regional sweat gland density. The present study has provided detailed regional sweat data over the whole body and has demonstrated large intra- and inter-segmental variation and the presence of consistent patterns of regional high versus low sweat rate areas in Caucasians male athletes. This data may have important applications for clothing design, thermophysiological modelling and thermal manikin design.

Keywords: sweating, exercise, metabolic rate, regional, sweat mapping 


\section{Introduction}

Under conditions of high ambient temperature and exercise, evaporation of sweat is typically the greatest avenue of heat loss from the body, and therefore important in maintaining body core temperature. Even in low temperatures, when protective clothing is worn, the body depends upon this mechanism to prevent overheating (Havenith et al. 2008b). This explains the interest of many research studies on sweat production and its regulation (Cotter et al. 1995; Havenith et al. 2008a; MachadoMoreira et al. 2008a, b, c; Nadel 1979; Nadel et al. 1971b, c; Taylor et al. 2006). Sweat production in different situations forms the basis for the available cooling power, which is modulated by aerobic fitness, acclimation state, environmental conditions, clothing, and evaporative efficiency (Candas et al. 1979; Havenith et al. 2008b; Shapiro et al. 1982).

Considerable literature is available on global or 'whole body' sweating but there have been limited studies on regional sweat rates (RSR). Renewed interest in RSR data has recently originated from both academic and commercial communities (Fiala et al. 1999, 2001; Havenith et al. 2008a; Machado Moreira et al. 2008a, b, c; Smith et al. 2007; Taylor et al. 2006). Sweat production in different body regions is relevant in the analysis of the body's heat exchange since clothing cover varies over different body parts, in addition to regional heat transfer coefficient differences resulting from air and body movement. In thermophysiological modelling, RSRs are therefore a relevant factor (Fiala et al. 1999; Havenith 2001b). Furthermore, the expansion of sweating thermal manikin use demands the availability of realistic RSR data (Havenith et al. 2008b), in addition to the potential benefits in the functional design of protective clothing and sportswear from knowledge on body sweat mapping. 
Those that have investigated regional sweating observed considerable variation between the sites tested (Cotter et al. 1995; Fogarty et al. 2007; Havenith et al. 2008a; Hertzman 1957; Kuno 1956; Machado-Moreira et al. 2008a, b, c; Ogata 1935; Smith et al. 2007; Taylor et al. 2006; Weiner 1945). These studies consistently found sweat rates of the sampled sites to be greatest on the torso. In particular the lumbar region of the posterior torso showed one of the greatest sweat rates over the body, in addition to the forehead. Lowest sweat rates were observed on the extremities, particularly on the palmar and plantar surfaces of the hands and feet respectively. However, to our knowledge, no study is available that provides quantitative data on RSRs for the majority of the body surface area. Bringing together data from different studies in a meta-analysis for the formation of a whole body sweat map has not been possible. The main problem with comparing much of the work conducted on RSR is that the observed values relate to the thermal state of the body and so results may not be directly comparable between studies when differing ambient temperatures, exercise modes, exercise intensities, clothing or heating techniques are used. Furthermore, due to sweat capsules being the predominant method for sweat measurement (Cotter et al. 1995; Hertzman 1957; Kuno 1956; Machado-Moreira et al. 2008a, b, c; Nadel et al. 1971b; Ogata 1935; Smith et al. 2007; Taylor et al. 2006; Weiner 1945) most studies only measure a small number of sites using a limited surface area $\left(3-12 \mathrm{~cm}^{2}\right)$, typically covering less than $2 \%$ of the body region, and generalise this data to larger regions. A technique allowing the simultaneous measurement of a large number of sites across the body is therefore required to quantitatively assess the regional relationships. 
The aim of this study was therefore to produce a detailed regional sweat map for male Caucasian athletes, covering the majority of the surface area of the body, which may be used in thermo-physiological modelling, in the advancement of thermal manikin design, and commercially in the design of clothing. It was hypothesised that significant intra-and inter segmental differences would be present over the body and that regional sweat rate differences visible at low work rates would be reduced when work rate was increased. Further, based on the classic work by Nadel et al. (1971a, b) it was hypothesised that local sweat rates would be strongly related to local skin temperature.

\section{Methods}

\section{Participants}

Nine male, unacclimated (for climate exposure, but probably part acclimated based on physical training) elite to sub-elite runners participated in whole body (WB) sweat mapping experimentation. A further experiment mapping sweat rates of the head, face and neck (HFN) was performed using nine male participants, four of which were from the initial WB sweat mapping group. All experimental procedures were approved by the Loughborough University Ethical Committee and were fully explained to the participants before obtaining informed written consent and completing a healthscreen questionnaire.

\section{Pre-Test Session}

Participants were required to attend the Thermal Environments Laboratory for a pretest session involving anthropometric measurements of height, mass, and body 
dimensions used for the calculation of body surface area (Dubois and Dubois 1916) and absorbent pad sizes. Skinfolds were taken using a 7 point calliper method (Jackson and Pollock 1978) specific to male athletes for calculation of body fat percentage. Aerobic fitness level, expressed as maximal oxygen uptake ( $\dot{\mathrm{V}}_{2}$ max $)$, was calculated from a sub-maximal fitness test based on the Åstrand-Ryhming method (American College of Sports Medicine 2006). The test was conducted at an ambient temperature of $18^{\circ} \mathrm{C}$ to prevent thermal stress and comprised of four exercise intensities running on a treadmill (h/p/cosmos mercury $4.0 \mathrm{~h} / \mathrm{p} / \operatorname{cosmos}$ sports \& medical gmbh, Nussdorf-Traunstein, Germany) each lasting five minutes. Estimation of $\dot{\mathrm{VO}}_{2}$ max was based upon the linear relationship between heart rate and work rate (based upon treadmill speed and angle (Epstein et al. 1987).

\section{Sweat Pad Preparation and Application}

RSRs were determined by applying absorbent material directly to the skin for a short, predefined, period of time. Two sets of absorbent pads were produced for each participant based on the pre-test anthropometric data (details of pad sizing and placement are available as electronic supplementary material (ESM) online from the EJAP website; ESM 1). These were weighed (Sartorius YACOILA, Sartorius AG, Goettingen, Germany. Precision 0.01g) inside individually labelled airtight bags, in which they were stored until testing. A total of $70 \mathrm{WB}$ and 15 HFN pads were used to produce a sweat map for each exercise intensity (for details see ESM 2). Pads were attached to custom made plastic sheeting for fast application to the body and to prevent the evaporation of sweat during the test periods. The pads were kept in place against the skin using a stretch long sleeve t-shirt and trousers. On the feet, pads were 
secured in place on the ankles and dorsal surface of the foot inside $100 \%$ cotton socks which were also used to collect sweat from the top of the foot. Plastic stretch socks were worn to prevent evaporation of sweat from the cotton socks during the measurement period. Similarly, $100 \%$ cotton gloves were worn to collect sweat on the hands, with small incisions made at the base of each finger to prevent the migration of sweat between regions, while maintaining their structural integrity during the test. Latex gloves were worn over the cotton gloves during the measurement period to secure the gloves in place against the skin and prevent sweat evaporation. HFN pads were produced in the same manner as the WB pads; however application to the face and neck required the pads to be lightly taped in place. Head pads were taped together in a lattice formation before being placed on the skin. Four participants shaved their heads to allow the application of these pads. All HFN pads were then secured in place using a single length of Bandafix@ pulled over the head.

\section{Experimental protocol}

A series of experimental sessions were conducted in a climate controlled room at 25.6 $\pm 0.4^{\circ} \mathrm{C}, 43.4 \pm 7.6 \%$ relative humidity, and a $2 \mathrm{~m} . \mathrm{s}^{-1}$ frontal air velocity, to progressively sweat map the body. To minimise the effect of the pads on the overall thermal state of the body, the WB sweat mapping was separated into three experimental sessions, each measuring about one third of the zones while allowing enough exposed skin for thermoregulation: 1) torso/upper body (UB), 2) legs, and 3) arms, hands, buttocks, and feet (AHBF). The testing sequence of body regions was balanced to prevent any order effect and each participant performed their experiments at the same time of day to minimise circadian variation. On arrival to the laboratory participants were provided with shorts and t-shirt and then weighed. Infra red images 
(Thermacam B2, FLIR Systems Ltd., West Malling, Kent, UK) of the nude, dried, skin were taken prior to testing, before and after each pad application, and immediately after testing to monitor $\mathrm{T}_{\mathrm{sk}}$. Resting heart rate (HR) was recorded before participants warmed up, with HR monitored throughout the experiment at 15 second intervals. $\mathrm{T}_{\text {core }}$ was measured using a VitalSense Integrated Physiological Monitoring System (Mini Mitter Company, Inc. Bend, Oregon, USA). Participants swallowed a CorTemp ${ }^{\mathrm{TM}}$ ingestible temperature pill 5 hours before testing. Throughout the experiment the VitalSense monitor wirelessly tracked and recorded $T_{\text {core }}$ four times per minute. Participants ran for a total of 60 minutes involving two exercise intensities of 30 minutes each on the treadmill with an incline of $1 \%$. The target HR was 125135 and 150-160 beats per minute (bpm) for intensity 1 (I1) and intensity 2 (I2) respectively, in order to control workload at the targets of 55 and $75 \%$ of $\dot{\mathrm{VO}} 2$ max. Sweat samples were taken for the last 5 minutes of each exercise intensity at 30 minutes and 60 minutes. Participants removed their clothing and towelled their skin dry immediately prior to pad application to ensure only sweat produced during the sample period was collected. All of the pads had an impermeable backing to prevent evaporation. Immediately following the sample period the pads were quickly returned to their airtight bags and sealed. The participants could drink water freely during the experiment, which was recorded, in order to prevent dehydration. Following the 60 minute run a final weight of the participant was recorded. On completion of the experimentation all pads were re-weighed inside their sealed bags. Unlike the absorbent pads, the cotton glove and sock segments could not be individually weighed before testing as they were not yet separated from each other. Immediately following sweat collection, specific sections of the gloves and socks were dissected and placed 
in individually labelled airtight bags. The post test weight of each sample was recorded before being dried out in a thermal chamber at $30^{\circ} \mathrm{C}, 50 \%$ rh for 24 hours then re-weighed to obtain the 'dry' (pre test) weight. The surface area of each pad was calculated from the dry weight of each pad and the weight per unit of surface area of the material. Sweat rate was calculated in grams per meter square of body surface area per hour $\left(\mathrm{g} \cdot \mathrm{m}^{-2} \cdot \mathrm{h}^{-1}\right)$ using the weight change of the pad, the pad surface area, and the length of time the pad was applied to the skin.

\section{Analysis}

As data from the different experimental sessions were to be combined in a whole body sweat map, and as sweat rates may differ slightly between sessions for an individual, it was decided to correct individual session data in line with the session's gross sweat loss (GSL) value. Data for each individual were standardised towards the mean GSL over all three WB sessions for that individual. A similar correction was applied to the head data, using the subjects who completed both the WB and HFN test as a reference. This resulted in a correction for the head session GSL towards the mean of the other 3 sessions, and in a correction for the difference between the two groups. All corrections work on the assumption that within each work load there is a relation between regional and GSL for an individual. Finally, as the present data provide whole body sweat rate by GSL and also allow (area weighted) summing up of all local sweat rates to produce a total body sweat rate ( $\left.\sum \mathrm{RSR}\right)$ it was possible to compare the two values. A correction of RSR values based on the difference between GSL and $\sum$ RSR data is therefore possible. This correction was however not applied to the present data since it only affects absolute RSR values (by a fixed factor), but does not change the sweat distribution pattern data. 
GSL was calculated based on the weight change of each participant across each test period and adjusted for fluid intake. Corrections were made for respiratory and metabolic mass losses. Evaporative loss from respiration ( $E_{\text {res }}$, Watts) was calculated using equation (1), based upon work described by Livingstone et al. (1994):

$$
E_{\text {res }}=1.27 \cdot 10^{-3} \cdot M\left(59.34+0.53 \cdot T_{a}-11.69 \cdot P_{a}\right)
$$

And converted into mass loss (g):

$$
\text { Mass Loss }=E_{\text {res }} \cdot t \cdot \frac{1}{2430}
$$

Where;

$E_{\text {res }}$ evaporative loss from respiration (W)

M metabolic rate (W)

$T_{a}$ air temperature $\left({ }^{\circ} \mathrm{C}\right)$

$t$ time: duration of intensity or experiment (s)

2430 , latent heat of evaporation of 1 gram of water $\left(\mathrm{J} \mathrm{g}^{-1}\right)$

Metabolic mass loss (g) was calculated from an equation taken from Bakkevig and Nielsen (1995), based upon Kerslake (1972, Pp. 121):

$$
\text { Metabolic mass loss }=\left(\frac{V o_{2}(44 \cdot R Q-32)}{22.4}\right) \cdot t
$$

Where;

$\dot{\mathrm{V}} \mathrm{O}_{2}$ rate of oxygen consumption (L.min $\left.{ }^{-1}\right)$

$R Q$ respiratory quotient (ND)

$t$ time (s) 
The respiratory quotient ( $R Q$ ) was taken as 0.85 for intensity 1 and 1.00 for intensity 2 (Parsons, 2003. pp 135).

Sweating sensitivity for each segment (i) was calculated as:

$$
\begin{gathered}
\operatorname{Gain}_{1, i}=\frac{\text { Sweat rate increase Intensity } 1}{\text { Core Temperature increase Intensity } 1} \\
\operatorname{Gain}_{2, i}=\frac{\text { Sweat Rate Intensity } 2 \text { - Sweat Rate Intensity } 1}{\text { Core Temperature increase Intensity } 2}
\end{gathered}
$$

Finally, overall sweat sensitivity was calculated for comparison with literature (Taylor et al. 2006, Machado-Moreira et al. 2008a, b, c) as:

$$
\text { Overall Gain }_{i}=\frac{\text { Sweat Rate Increase over Experiment }}{\text { Core Temperature Increase over Experiment }}
$$

Paired samples t-tests were performed both with and without Bonferroni correction to analyse right-left differences in sweat rate and changes with exercise intensity. A oneway repeated measures ANOVA was performed to analyse regional differences within each intensity, presented both with and without Bonferroni correction for posthoc comparisons. The reasons for showing both to the reader are firstly the exploratory nature of the study and secondly the large number of zones studied compared to any earlier study (Bender and Lange 1999; Perneger 1998). This makes the Bonferroni correction very stringent and zones that would show significance in a smaller study will struggle to reach significance here. Pearson's correlation coefficient was calculated to assess correlations between RSRs and regional $\mathrm{T}_{\text {sk, }}$ and 
RSRs and GSL. Finally, it was decided that it would be more relevant to graphically show results for the 'average sweater' (the median) rather than the 'average amount of sweat produced' (the mean), as the latter can be affected more easily by outliers, i.e. extreme sweaters. In tables, both values are presented to provide insight into the data distribution.

\section{Results}

The physical characteristics (mean \pm SD) of participants involved in WB sweat mapping and HFN sweat mapping are provided in Table 1. No significant differences in physical characteristics were present between WB and HFN groups with exception to $\dot{\mathrm{V}} \mathrm{O}_{2 \text { max }}$ being significantly lower in the HFN participants $(\mathrm{p}<0.05)$.

Insert Table 1 approximately here.

\section{Core Temperature, Work Rate, and Heart Rate}

Baseline (BL) data were taken as the temperature recorded immediately before commencing I1. I1 and I2 results were analysed as the mean $\mathrm{T}_{\text {core }}$ over the final five minutes of each intensity. As expected, $\mathrm{T}_{\text {core }}$ increased significantly during both exercise intensities. For $\mathrm{WB}, \mathrm{T}_{\text {core }}$ rose from $36.93 \pm 0.39$ at $\mathrm{BL}$ to $37.68 \pm 0.43$ $(\mathrm{p}<0.001)$ at the end of I1 and to $38.06 \pm 0.42(\mathrm{p}<0.001)$ at the end of I2. For HFN, $\mathrm{T}_{\text {core }}$ increased significantly from $37.23 \pm 0.32$ at $\mathrm{BL}$ to $37.79 \pm 0.15$ at $\mathrm{I} 1(\mathrm{p}<0.01)$ and $38.17 \pm 0.07$ at the end of $\mathrm{I} 2(\mathrm{p}<0.05)$. No significant differences were present between WB or HFN groups for $\mathrm{T}_{\text {core, }}$ or work rate $\left(\dot{\mathrm{VO}}_{2}\right)$ at any time point. HR was 
significantly higher at BL in the HFN group $(\mathrm{p}<0.05)$, with values of $75 \pm 19 \mathrm{bpm}$ and $59 \pm 9$ bpm respectively but was not different thereafter.

\section{Gross Sweat Loss}

Considerable variation in GSL was observed both within individuals (between sessions) and between individuals. The overall mean GSL of all sweat mapping experiments (WB and HF) was $458 \pm 115 \mathrm{~g} \cdot \mathrm{m}^{-2} \cdot \mathrm{h}^{-1}$, with the mean of all WB experiments being $489 \pm 107 \mathrm{~g} \cdot \mathrm{m}^{-2} \cdot \mathrm{h}^{-1}$. Mean GSL values for the different sessions were $524 \pm 98,445 \pm 98$, and $499 \pm 121 \mathrm{~g} \cdot \mathrm{m}^{-2} \cdot \mathrm{h}^{-1}$ for the torso/upper body (UB), legs, arms, hands, buttocks and feet (AHBF), and $365 \pm 86 \mathrm{~g} \cdot \mathrm{m}^{-2} \cdot \mathrm{h}^{-1}$ for the head, face and neck (HFN) tests respectively. The covered surface areas in these sessions were $0.38 \mathrm{~m}^{2}$ (UB), $0.51 \mathrm{~m}^{2}$ (legs), $0.58 \mathrm{~m}^{2}$ (AHBF) and $0.13 \mathrm{~m}^{2}$ (HFN). WB and HFN GSL increased significantly $(\mathrm{p}<0.001)$ with exercise intensity, from $364 \pm 84$ to $657 \pm$ 119 g.m $\mathrm{m}^{-2} \cdot \mathrm{h}^{-1}$ for WB and from $255 \pm 66$ to $513 \pm 131 \mathrm{~g} \cdot \mathrm{m}^{-2} \cdot \mathrm{h}^{-1}$ for HFN.

GSL correlated positively with $\dot{\mathrm{VO}}_{2 \max }(\mathrm{WB} \mathrm{r}=0.88, \mathrm{p}<0.001 ; \mathrm{HFN} \mathrm{r}=0.77, \mathrm{p}<0.05)$. For the individual work intensities (Figure 1), GSL (g.h ${ }^{-1}$ ) correlated positively with metabolic rate $(\mathrm{W})$ for both WB and HFN (I1: WB $r=0.86, \mathrm{p}<0.01$, HFN r $=0.70$, $\mathrm{p}$ $<0.05$; I2: WB $\mathrm{r}=0.72, \mathrm{p}<0.05, \mathrm{HFN} \mathrm{r}=0.76, \mathrm{p}<0.05$ ). No significant difference was present between the gradients of the regression lines for I1 and I2 within each group, or between groups for each intensity. The intercept (constant) was not significantly different between exercise intensities in either group.

Insert Figure 1 Approximately here. 


\section{Regional Sweat Rates}

The comparison of GSL and the area weighted sum of all determined local sweat rates ( $\sum \mathrm{RSR}$ ) revealed that GSL was $22 \%$ higher than $\sum \mathrm{RSR}$. No correction factor was applied to the RSR data due to having no affect upon distribution. However, a correction factor of 1.22 may be applied to the absolute RSR values to adjust for the difference between $\sum$ RSR and GSL.

It was decided to group WB RSR data for right and left corresponding zones for all analyses since any significant differences represented only a small number of the 70 individual zones sampled (right-left differences without Bonferroni correction: I1 shoulders, anterior upper leg, anterior lower arm, and dorsal hand $(\mathrm{p}<0.05)$; I2 anterior medial lower leg $(\mathrm{p}<0.01)$, anterior upper arm $(\mathrm{p}<0.05)$, and anterior lower arm $(\mathrm{p}<0.05)$; Following Bonferroni correction: I2 anterior medial leg $(\mathrm{p}<0.01)$. All sweat rates were higher on the right hand side of the body with exception of the shoulders. When comparing right vs. left in the HFN data, a mixture of right and left zones were significantly higher, however comparing all HFN zones, no lateral head pads were significantly different from each other on a single side of the body. On balance it was decided to group the HFN data into forehead, cheeks, chin, medial head, right lateral head and left lateral head for analysis. The main reason for grouping areas was to reduce the number of comparisons to be made between zones and thus reducing the Type I error in the analysis.

Median grouped data for all participants are illustrated for both exercise intensities in Figure 2 and Figure 3 respectively. WB and HFN data are presented together in the figures after correcting the HFN values based on results for the subjects who 
performed both experiments. The pads indicated in grey, located below the anterior and posterior neck and at the axilla, were designed to absorb any excess sweat which may have dripped from these areas and avoid it being absorbed by neighbouring pads. These extra pads were discarded following testing and were not used in sweat mapping calculations.

Insert Figure 2 and 3 approximately here

Due to the exploratory nature of the sweat mapping study it was decided to perform a comparison of all regions within each exercise intensity. The design was treated as repeated measures since each measurement was performed on the same individual. Each region is not strictly repeated measures since different areas (variables) are measured, yet nor are they independent from each other when measuring multiple regions on the same individual. It was decided to use a repeated measures ANOVA to allow regional comparison, with adjustment for multiple comparisons. Data were analysed both with and without Bonferroni correction due to the exploratory nature of the study and the conservative nature of the Bonferroni correction. For comparisons of all WB regions please refer to electronic supplementary material 3 available online from the journal (ESM-3).

For presentation in Figure 4 and 5, RSRs were normalised for the area weighed sweat rate of all zones for each individual and then a median of all individuals was taken. Normalised sweat rate allowed standardisation of data over participants and allowed easy identification of 'higher' and 'lower than average' sweat regions over both intensities, despite different absolute sweat rates. Areas with sweat rate ratios 
significantly different from average $(=1)$ are indicated in Table 2 by a grey background in the ratio columns.

Insert figure 4 and 5 approximately here

The low sweat rates of the extremities compared to the torso are clearly present with little change in distribution from I1 to I2. A medial to lateral decrease across the torso is equally clear, while the reverse occurs on the head. A comparison of sweat rates within each region from I1 to I2 was performed using a series of paired t-tests and corrected for multiple comparisons (Table 2). Data are presented both with and without Bonferroni correction in addition to descriptive statistics for all regions tested. $81 \%$ of the zones showed a significant increase in absolute sweat rates from I1 to I2 and even with the stringent Bonferroni correction applied, close to a third of the zones still achieved significance.

Insert Table 2 approximately here

The large variation between participants is clearly evident from the minimum and maximum values within each region. For most zones, median and mean values are very close. Where they are not, usually the mean is highest, typically caused by a single 'high sweater' in the group. The normalised data indicates little change in regional distribution between intensities, with exception to a significant decrease in the relative sweat ratio over the feet. When corrected for multiple comparisons no significant differences were present in the normalised data between I1 and I2. Sweat sensitivity data are also presented in Table 2. For intensity 1, these may be 
underestimations of the actual values since sweat onset is typically $0.2-0.3^{\circ} \mathrm{C}$ above baseline and does not occur simultaneously over the body. In many participants sweating was nevertheless observed almost immediately with exercise, probably due to a warm up in the preparation period in the warm chamber. For intensity 2 this problem is not present. As sweat sensitivity for individuals showed some outliers to extreme values, it was decided to use median values, i.e. sensitivity for the median sweater.

\section{Skin Temperature}

Regional $T_{\text {sk }}$ data were right-left grouped for analysis due to only 6 significant rightleft differences out of the 44 regions measured for WB sweat mapping. These differences were not consistently higher over one side of the body or across time points, and were not significant following Bonferroni correction. Only the feet and ankles showed a significant increase in $\mathrm{T}_{\mathrm{sk}}$ from $\mathrm{BL}$ to pre $\mathrm{I} 1$ pad application, reflecting their low $\mathrm{BL}$ temperatures (uncorrected: heels $\mathrm{p}<0.01$, soles $\mathrm{p}<0.001$, dorsal foot $\mathrm{p}<0.001$, ankles $\mathrm{p}<0.05$ ). The heels showed the lowest $\mathrm{BL} \mathrm{T}_{\mathrm{sk}}$ of $25.8^{\circ} \mathrm{C}$ compared to $32.5^{\circ} \mathrm{C}$ on the anterior upper arm. Of particular interest was the change in $\mathrm{T}_{\mathrm{sk}}$ between pre and post pad application at both exercise intensities, as this reflects the impact of the procedure on $\mathrm{T}_{\mathrm{sk}}$. The mean increase in $\mathrm{T}_{\mathrm{sk}}$ over all regions during pad application was $0.9^{\circ} \mathrm{C}$ during $\mathrm{I} 1$ and $0.8^{\circ} \mathrm{C}$ during $\mathrm{I} 2$.

During HFN testing skin temperature increased significantly from pre pad application in $\mathrm{I} 1$ to post pad removal in $\mathrm{I} 1$ at all tested regions, whilst local $\mathrm{T}_{\mathrm{sk}}$ increased significantly at only four regions from pre I2 to post I2 pad application. After Bonferroni correction this decreased to 2 regions following I1 pad application and 
only 1 after I2. Notably, the face and neck appeared to be affected more by pad application compared to the head, with regions on the face and neck increasing significantly following I1 and I2 pad application. $\mathrm{T}_{\mathrm{sk}}$ showed no significant change on the posterior head following I1 pad application and no increase at any region at I2. The mean increase in $\mathrm{T}_{\mathrm{sk}}$ of all regions was $1.7^{\circ} \mathrm{C}$ during $\mathrm{I} 1$ and $\mathrm{I} 2$ pad application for HFN.

A Pearson's $r$ correlation analysis was performed between RSR and respective regional $\mathrm{T}_{\mathrm{sk}}$ for each individual. Within participant analysis was performed due to between participant factors potentially confounding regional $\mathrm{T}_{\mathrm{sk}}$ and sweat rate. In particular, participants worked at differing absolute work rates producing varied absolute sweat rates. Since significant differences were present in $\mathrm{T}_{\mathrm{sk}}$ between pre and post pad application, sweat rate was compared with both $\mathrm{T}_{\mathrm{sk}}$ measurements separately. For the WB data no significant correlation was observed at I1 or I2. In the HFN data a small number of strong correlations were observed, with a mixture of positive and negative $\mathrm{r}$ values (m14, post $\mathrm{I} 1 \mathrm{r}=-0.91, \mathrm{p}=0.09$; $\mathrm{m} 15$, pre $\mathrm{I} 1 \mathrm{r}=-0.77$, $\mathrm{p}<0.05$, post I1 $\mathrm{r}=-0.73, \mathrm{p}<0.05$; m9, post I2 $\mathrm{r}=-0.77, \mathrm{p}=0.232 ; \mathrm{m} 13$, post $\mathrm{I} 2 \mathrm{r}=$ 0.86, $\mathrm{p}=0.139$ ). No participant demonstrated a significant and consistent correlation between regional $\mathrm{T}_{\text {sk }}$ and RSR across measurement periods.

\section{Discussion}

The present study aimed to produce a whole body map of sweat distribution in Caucasian male athletes at two exercise intensities in warm conditions. The results have clearly demonstrated significant regional variation in sweat rates both within and 
between body segments and that the variation in absolute sweat rate is considerable between individuals. Despite large individual variation in the quantity of sweat produced, a number of patterns in RSR were observed in the majority of participants: 1) sweat rate increased significantly with exercise intensity in all regions except the feet and ankles, 2) the posterior torso consistently showed the highest sweat rates over the whole body at both I1 and I2, with exception only to the forehead, 3) lowest sweat rates were observed on the hands, feet, cheeks and chin at I1 and the hands and feet at I2, 4) sweat rates tended to be higher on the dorsal compared to the plantar surface of the feet at both I1 and I2, and similarly higher on the dorsal compared to palmar surface of the hands, 5) a medial to lateral decrease in sweat rate was present across the torso, 6) an increase in sweat rate from proximal to distal regions on the arms, and 7) a medial to lateral decrease on the head, although not statistically significant. After normalisation of the individual data, a pattern of high and low sweat distribution was observed, with significant differences in sweat output ratio between regions. Most regions were quite consistently $(\mathrm{p}<0.05)$ either lower OR higher than average $(=1)$, as indicated by the grey background for the normalised ration data in Table 2 . Comparing the normalised sweat map patterns between the two work intensities did not show the hypothesized equalisation of sweat rates at higher work rates. The overall pattern remained the same, and only a few areas showed significantly different sweat rate ratios. A levelling off of sweat rate was observed in the feet and ankles, suggesting maximal values may be reached at low levels of thermal stimulation. This may not be surprising since the feet are not a region of high thermally-induced sweat output (Taylor et al. 2006), and are under sympathetic adrenergic vasoconstrictor control. In contrast, nonglabrous skin exhibits significantly greater sweat rates than glabrous skin and is innervated via dual vasoconstrictor and cholinergic vasodilator 
nerves. The lower skin blood flow in conjunction with the lower thermal sweating present in glabrous skin supports the hypothesised relationship between sweat rate and blood flow (Fox and Edholm 1963; Love and Shanks 1962; Rowell 1977).

The large difference in absolute RSR between participants reflects the observed variation in GSL. Since all participants were working at a similar percentage of $\dot{\mathrm{V}} \mathrm{O}_{2}$ max for each exercise intensity, resulting in similar $\mathrm{T}_{\text {core, }}$ the correlation between GSL and predicted $\dot{\mathrm{VO}}_{2}$ max reflects the difference in absolute work rate between participants (Havenith 1985, 1997, 2001a, b; Kenny and Jay 2007; Nielsen 1969). This was demonstrated by the strong, significant correlation between GSL and metabolic rate in both groups (Figure 1). No significant difference in the gradient of the regression lines was present between intensities in the WB or HFN groups, indicating no change in the relation between sweat rate and work rate (metabolic rate) between exercise intensities. In Fig. 1, absolute sweat rate and metabolic rate (g. $\mathrm{h}^{-1}$ vs. watt) are presented rather than the surface area corrected values $\left(\mathrm{g} \cdot \mathrm{m}^{-2} \cdot \mathrm{h}^{-1} \mathrm{vs} . \mathrm{w} \cdot \mathrm{m}^{-2}\right)$. The latter, though more commonly used, also show a significant correlation, though less strong. It was felt that the absolute amount of heat generated (W) and the absolute cooling power $\left(\mathrm{g} \cdot \mathrm{h}^{-1}\right)$ represented the data best.

The present RSR data supports the well documented variation in eccrine sweating (Cotter et al. 1995; Hertzman 1957; Kuno 1956), with the highest values on the posterior torso, in particular on the central upper, central mid, and lower back. The anterior torso and shoulders followed as areas of next highest sweat production, yet values were over half that of the central posterior torso. The lowest sweat rates were 
observed on the extremities, particularly the feet, palms, and fingers. The regional variation observed in the present study is largely supported by the classic, mainly qualitative work of Kuno (1956 pp. 193-195) and more recently by studies looking in detail at large regions and intra-regional variation; Taylor et al. (2006 feet), Fogarty et al. (2007 feet), Smith et al. (2007 hands and arms), Havenith et al. (2008a torso), and Machado-Moreira et al. (2008a hands, b torso, c head). In agreement with the current findings, they identified areas of high sweat production to be the forehead, neck, large areas of the anterior and posterior trunk, and the lumbar region. Areas of low sweat production were observed to be the sides of the chest, all extremities, and the internal femoral region. In contrast to the present data, Weiner (1945) found lower sweat rates on the posterior compared to anterior torso, however, the small sample size $(n=3)$ may have been inadequate given the high variation in sweating between individuals. A medial to lateral decrease in sweat rate was observed across the torso in the present study and was similarly noted by Machado-Moreira et al. (2008b) and Havenith et al. (2008b), but not by Cotter et al. (1995). Hertzman (1957) and Weiner (1945) similarly found lower sweat rates along the axillary line, supporting the present data. Kuno’s (1956) suggestion in his qualitative data based on passive heating, that Japanese males may be classified into four sweat categories based upon body regions exhibiting the greatest sweat rates, were not confirmed for Caucasian males in the present test involving exercise induced heating. The sweat mapping data indicated the majority of the participants to display similar high and low sweat areas (grey shading for ratio data in Table 2). Notably, the distribution of the data for the different zones was 'normal' as illustrated by the closeness of means and medians in the RSR data in Table 2. It was observed that where the distribution was skewed, this was typically due to an 'extreme sweater'. 
HFN data showed the highest sweat rate at both exercise intensities to be on the forehead and the lowest to be the cheeks and chin, though the latter two showed a wide range of sweat ratios over participants. The forehead had the highest sweat rate and the highest sudomotor sensitivity of the whole body. Machado-Moreira and colleagues (2008c) observed a significant increase from medial to lateral regions on the head. Although not significant, the lateral head did show higher sweat rates than the medial regions in the present data. As not all subjects were willing to shave their heads $(n=4)$, the lower $n$ here has reduced statistical power.

Some consideration is needed when discussing the head data in relation to the rest of the body, as only four participants completed both the WB and the HFN testing. In order to include the information of the other four participants in the HFN testing their data were corrected based on the GSL differences between the two test groups. This correction and the correction of the WB data between the different region sessions, is based on the assumption of a strong relation between RSR and whole body sweat rate (over the rather narrow range of GSL needed for the correction), and on a good correlation between GSL and work rate for a given relative intensity (the latter would adjust for differences in $\dot{\mathrm{V}}_{2}$ max). Both requirements are met in the data. Strong and significant correlations of RSR and GSL are present for most regions (Table 2) and also GSL and work rate are strongly linked (Figure. 1). Though other authors have also combined data from different time points or test sessions (moving capsules around the body) into the same paper (Cotter et al. 1995; Machado-Moreira et al. 
2008a, b, c), to our knowledge none have applied a correction for inter-session differences.

The hypothesized relation between RSR and local $\mathrm{T}_{\text {sk }}$ was not evident in the present data. Nadel et al. (1971a, b) modelled sweat rates based on $\mathrm{T}_{\text {core }}$, mean $\mathrm{T}_{\text {sk }}$ and local $\mathrm{T}_{\text {sk }}$. Though the effect of $\mathrm{T}_{\text {core }}$ is evident when looking at the I1 and I2 differences, the effect of local $\mathrm{T}_{\text {sk }}$ was not effective in explaining any of the fluctuations between regions. Fluctuations in $\mathrm{T}_{\mathrm{sk}}$ arise from resultant fluctuations in regional blood flow and in sweat evaporation, reflecting the balance between heat production, sweating and cooling. This dynamic interplay of $\mathrm{T}_{\mathrm{sk}}$ and RSR may explain the weak correlation observed. Cotter et al. (1995) observed similar results, with a low correlation between local $\mathrm{T}_{\mathrm{sk}}$ and RSR during transient sweating $(\mathrm{r}=0.16)$, and only $2.5 \%$ of steady state sweating being explained by variation in local $\mathrm{T}_{\mathrm{sk}}$. A further consideration is the possible influence of the front wind used in the current study upon sweat evaporation, $\mathrm{T}_{\text {sk }}$ and RSR distribution (most other studies had no relevant air movement). Since the presence of wind is known to increase evaporative heat loss, this may affect not only total sweat rate but RSR through its effect of lowering local $T_{\text {sk. }}$. This specific question was studied by Smith et al. (unpublished) during exercise in three conditions (no wind, front wind, back wind using $2 \mathrm{~m} . \mathrm{s}^{-1}$ air velocity). No significant differences in the $\mathrm{T}_{\mathrm{sk}}$ or changes in sweat ratio distribution between the anterior and posterior torso were observed between any of the conditions. This is consistent with current literature since higher RSR on the posterior compared to anterior torso have been observed both with (Havenith et al. 2008a) and without the presence of wind (Machado-Moreira et al. 2008b). Overall, regarding the influence of local $\mathrm{T}_{\mathrm{sk}}$, it is concluded that when substantially changing it locally a clear effect is present (Nadel 
et al. 1971a), but when looking at the natural variation over the body, as done here, this effect is of minor importance.

Apart from the lack in predictive power of $\mathrm{T}_{\mathrm{sk}}$, the observed regional sweat distribution also fails to correspond to literature data on sweat gland density (Ogata, 1935). Cadaver data by Szabó (1962) found the highest densities (glands.cm ${ }^{-2} \pm \mathrm{SEM}$ ) on the soles $(620 \pm 120)$, forehead (360 \pm 50$)$, and cheeks (320 \pm 60$)$. The lowest values were on the back, buttocks, lower legs, upper arms, and thighs with values from $160 \pm 30$ to $120 \pm 10$ respectively. The small cadaver samples reported by Szabó must however be noted, whilst in agreement with some studies (Krause , 1844, cited in (Szabo 1962)), debate does surround the exact numbers of regional sweat glands. A comprehensive review of torso sweat gland densities (active and inactive) from a large body of literature was recently produced by Machado-Moreira et al. (2008b), providing more reliable values. Mean glandular density was highest on the abdomen (115 glands.cm $\left.{ }^{-2}\right)$, upper back (104 glands.cm $\left.{ }^{-2}\right)$, chest (102 glands. $\left.\mathrm{cm}^{-2}\right)$ and the lower back (101 glands.cm²). Lower values were observed on the chest (sternal, mammary) and abdomen with values of 90, 21, and 81 glands.cm ${ }^{-2}$ respectively. Given the relatively uniform glandular density on the torso, the large variation in RSR there cannot be explained by the total number of glands. It would therefore seem logical to consider the number of active sweat glands, output per gland, and sudomotor sensitivity. Machado-Moreira et al. (2008a, b) calculated intra segmental sudomotor sensitivity, with results relating closely to the regional variation in sweat rate and sudomotor sensitivity observed in the current study (Table 2) supporting these factors as the likely explanation. 
Comparison between the present absolute data and the relevant literature is problematic since differing temperature and exercise protocols have been adopted or different participant groups were used for the study of different body parts (MachadoMoreira 2008a, b, c) without defining precise fitness levels ( $\dot{\mathrm{VO}}_{2}$ max $)$. The present study provides RSR data for a large surface area of the body in young, healthy, highly trained, Caucasian males and without further research should not be generalised to other populations. Discrepancies in data may also arise from methodological issues since some measuring techniques promote complete evaporation at the skin (ventilated capsules) which may artificially elevate sweat rate on one hand due to dry skin, but lower sweat rate on the other hand due to the cooling of the skin. Other methods prevent evaporation (absorbents), potentially leading to increases in $\mathrm{T}_{\mathrm{sk}}$ and thus sweat rate or due to moisture accumulation, inducing hidromeiosis and lowering sweat rate. For a more detailed discussion of sweat measurement techniques the reader is directed to Havenith et al. (2008a). It is worthy of note that any method employed in sweat measurement will interfere to some degree with the microclimate of the skin and hence the sweat rate.

In the present test, the sum of the sampled areas added up to the majority of the body surface area $\left(1.6 \mathrm{~m}^{2}\right.$ out of $1.92 \mathrm{~m}^{2}$, approximately $83 \%$ of total body $\left.\mathrm{SA}\right)$, uniquely allowing a comparison of local sweat sampling to overall sweating by adding up all local sweat rates ( $\mathrm{RSR}$ ) and comparing this to GSL. It was found that GSL was on average 22\% higher than $\sum$ RSR when all measured zones were included. As the methodology was identical for all sampled zones, this discrepancy should not affect the sweat distribution data. It was decided not to apply this factor as a correction to 
the absolute data, and only report the discrepancy. Causes for the discrepancy may be found in issues with the areas that were not sampled (overall $0.3 \mathrm{~m}^{2}$ was not included, while in each session at least $60 \%$ of the surface was uncovered), or in the sampling method itself: For the current method one needs to consider the effect of the application pressure, of increased humidity and of possible moisture accumulation under the pads. Application of pressure to the skin has, in a limited number of studies, demonstrated a suppressive effect on RSR whilst augmenting sweat rate in contralateral regions. This hemihidrotic effect was first recognised by Kuno in 1934 (1956) and later confirmed by Takagi and Sakurai (1950, cited in (Kuno 1956)), but not observed by Watkins (1956). For the present study this effect is however unlikely since the hemihidrotic reflex has been observed in instances of localised pressure applied to the axilla, has a latent period of several minutes, and requires considerably greater force than applied in the current study (Ferres 1960). As for moisture accumulation, under conditions of high skin wettedness, a decline in sweat rate may be observed due to epidermal swelling (Hidromeiosis). This however seems unlikely in the present test since hidromeiosis requires high levels of skin wettedness and develops over a much greater time period than used for pad application (Candas 1986; Candas et al. 1980; Kerslake 1972). Most importantly, the absorbent material used for sweat measurement possesses considerable hygroscopic properties (absorption capacity $=4655 \pm 220$ g.m ${ }^{-2}$, of which only $2.4 \%$ was used during testing) and therefore only under conditions of prolonged application could hidromeiosis pose a problem. On the other hand, an increase in relative humidity under the pads cannot be avoided (unless one would use a chemical bond for the moisture like in silica gel) and may have contributed to the difference between GSL and the sum of all locally measured sweat rates. 


\section{Conclusions}

In conclusion, despite large individual variation in absolute sweat rate, a consistent pattern of high versus low regional distribution was observed. Highest sweat rates were observed on the central and lower posterior torso (back) and forehead whilst the lowest values were observed towards the extremities. Both GSL and RSR increased significantly with exercise intensity, with exception to the feet, however, no significant change in distribution was observed. RSR cannot be explained by regional $\mathrm{T}_{\mathrm{sk}}$ or variation in sweat gland density, but may be explained by regional differences in sudomotor sensitivity and output per gland. To our knowledge, the present study provides the most detailed quantitative regional sweat data currently available for young Caucasian male athletes during exercise in warm conditions. These data are important both in terms of basic physiological data and for the development of thermophysiological models, sweating manikin design, and commercially for the design of clothing. Complementary data to extend these findings to females, untrained, and older populations is necessary, in addition to research examining regional skin blood flow and eccrine sweat gland sensitivity to elucidate the mechanisms underpinning regional sweat rate variation. 


\section{Acknowledgements}

The authors would like to acknowledge the continued support from the Adidas Innovation Team during this study, with special thanks to Berthold Krabbe, Brady Anderson, Jean Piere Roy and James Lamont.

\section{Conflicts of Interest}

The research presented was funded by the Adidas Innovation Team, Germany and the Department of Ergonomics (Human Sciences), Loughborough University. The authors were fully responsible for the conduct of the trial and the data. 


\section{References}

Bakkevig MK, Nielsen R (1995) Impact of activity level on sweat accumulation and thermal comfort using different underwear. Ergonomics 38:926-939

Bender R, Lange S (1999) Multiple test procedures other than Bonferroni's deserve wider use. BMJ 318: 600-601

Candas V (1986) Adaptation to extreme environments. Thermophysiological change in man during humid heat acclimation In: Dejours P (ed) Comparative physiology of environmental adaptations. Karger, Basel, pp. 76-93

Candas V, Libert JP, Vogt JJ (1979) Human skin wettedness and evaporative efficiency of sweating. J Appl Physiol 46: 522-528

Candas V, Libert JP, Vogt JJ (1980) Effect of hidromeiosis on sweat drippage during acclimation to humid heat. Eur J Appl Physiol Occup Physiol 44: 123-133

Cotter JD, Patterson MJ, Taylor NA (1995) The topography of eccrine sweating in humans during exercise. Eur J Appl Physiol Occup Physiol 71: 549-554

Dubois D, Dubois E (1916) A formula to estimate the approximate surface area if height and weight be known Arch Intern Med 17: 831-836

Du Bois, D., Du Bois, E. F. (1916) A formula to estimate the approximate surface area if height and weight be known. Arch. intern. Med.17, 863-871

Epstein Y, Stroschein LA, Pandolf KB (1987) Predicting metabolic costs of running with and without backpack loads. Eur J Appl Physiol 56: 495-500

Ferres HM (1960) The effect of pressure on sweating. J Physiol 151: 591-597

Fiala D, Lomas KJ, Stohrer M (1999) A computer model of human thermoregulation for a wide range of environmental conditions: the passive system. J Appl Physiol 87: 1957-1972

Fiala D, Lomas KJ, Stohrer M (2001) Computer prediction of human thermoregulatory and temperature responses to a wide range of environmental conditions. Int J Biometeorol 45:143-159

Fogarty AL, Barlett R, Ventenat V, Havenith G (2007) Regional foot sweat rates during a 65-minute uphill walk with a backpack. In: Mekjavic IB, Kounalakis SN, Taylor NAS (eds) Environmental Ergonomics XII, Biomed d.o.o., Ljubljana, Slovenia, pp. 266-269

Fox RH, Edholm OG (1963) Nervous control of the cutaneous circulation. Br Med Bull 19: 110-114

Havenith G (1985) Individual parameters in thermoregulatory control; a review. Report Institute for Perception IZF 1985-26.

Havenith G (1997) Individual heat stress response. Thesis, Nijmegen University,Ponsen and Looijen press, Wageningen, 1997, ISBN 90-9010979, http://dare.ubn.kun.nl/bitstream/2066/18586/1/18586_indihestr.pdf.

Havenith G (2001a) Human surface to mass ratio and core temperature in exercise heat stress - a concept revisited. J Therm Biol 26: 387-393

Havenith G (2001b) An individual model of human thermoregulation for the simulation of heat stress response. J Appl Physiol 90: 1943-1954

Havenith G, Fogarty A, Bartlett R, Smith CJ, Ventenat V (2008a) Male and female upper body sweat distribution during running measured with technical absorbents. Eur J Appl Physiol 104: 245-255

Havenith G, Richards MG, Wang X, Brode P, Candas V, den Hartog E, Holmer I, Kuklane K, Meinander H, Nocker W (2008b) Apparent latent heat of 
evaporation from clothing: attenuation and "heat pipe" effects. J Appl Physiol 104: $142-149$

Hertzman AB (1957) Individual differences in regional sweating. J Appl Physiol 10: 242-248

Jackson AS, Pollock ML (1978) Generalized equations for predicting body density of men. Br J Nutr 40: 497-504

Johnson JM, Proppe DW (1996) Cardiovascular adjustments to heat stress. In: Handbook of Physiology, Fregly, MJ, Blatteis, CM, eds. Section 4: Environmental Physiology. Vol 1. Oxford University Press, New York, NY

Kenny GP, Jay O (2007) Evidence of a greater onset threshold for sweating in females following intense exercise. Eur J Appl Physiol 101: 487-493

Kerslake D (1972) The stress of hot environments. Cambridge University Press, Cambridge

Kuno Y (1956) Human perspiration. Charles C. Thomas Publ., Springfield

Livingstone SD, Nolan RW, Cain JB, Keefe AA (1994) Effects of working in hot environments on respiratory air temperature. Eur J Physiol Occup Physiol 69: 98-101

Love AHG, Shanks RG (1962) The relationship between the onset of sweating and vasodilation in the forearm during body heating. J Physiol (Lond) 162: 121128

Machado-Moreira CA, Caldwell JN, Mekjavic IB, Taylor NA (2008a) Sweat secretion from palmar and dorsal surfaces of the hands during passive and active heating. Aviat Space Environ Med 79: 1034-1040

Machado-Moreira CA, Smith FM, van den Heuvel AM, Mekjavic IB, Taylor NA (2008b) Sweat secretion from the torso during passively-induced and exerciserelated hyperthermia. Eur J Appl Physiol 104: 265-270

Machado-Moreira CA, Wilmink F, Meijer A, Mekjavic IB, Taylor NA (2008c) Local differences in sweat secretion from the head during rest and exercise in the heat. Eur J Appl Physiol 104: 257-264

Nadel ER (1979) Control of sweating rate while exercising in the heat. Med Sci Sports 11:31-35

Nadel ER, Bullard RW, Stolwijk JA (1971a) Importance of skin temperature in the regulation of sweating. J Appl Physiol 31: 80-87

Nadel ER, Mitchell JW, Saltin B, Stolwijk JA (1971b) Peripheral modifications to the central drive for sweating. J Appl Physiol 31: 828-833

Nadel ER, Mitchell JW, Stolwijk JA (1971c) Control of local and total sweating during exercise transients. Int J Biometeorol 15: 201-206

Nielsen B (1969) Thermoregulation in rest and exercise. Acta Physiol Scand Suppl 323: $1-74$

Ogata K (1935) Functional variations in human sweat glands, with remarks upon the regional difference of the amount of sweat. J Oriental Med 23: 98-101

Parsons K (2003) Human thermal environments: The effects of hot, moderate and cold environments on human health, comfort and performance. London, Taylor and Francis.

Perneger TV (1998) What's wrong with Bonferroni adjustments. Br Med J 316: 12361238

Rowell LB (1977) Reflex control of the cutaneous vasculature. J Invest Dermatol 69: 154-166 
Shapiro Y, Pandolf KB, Goldman RF (1982) Predicting sweat loss response to exercise, environment and clothing. Eur J Appl Physiol Occup Physiol 48: 8396

Shibasaki M, Wilson TE, Crandall CG (2006) Neural control and mechanisms of eccrine sweating during heat stress and exercise. J Appl Physiol 100: 16921701

Smith CJ, Ventenat V, Havenith G (2007) Regional sweat rates of the arms and hands in male squash players. In: Mekjavic IB, Kounalakis SN, Taylor NAS (eds) Environmental Ergonomics XII, Biomed d.o.o., Ljubljana, Slovenia

Szabo G (1962) The number of eccrine sweat glands in human skin. In: Montagna W, Ellis RA, Silver AF (eds) Advances in biology of the skin. Pergamon Press, London, pp. 1-5

Taylor NAS, Caldwell FN, Mekjavic IB (2006) The sweating foot: Local differences in sweat secretion during exercise-induced hyperthermia. Aviat Space Envir Md 77: 1020-1027

Watkins ES (1956) The effect on sweating of pressure on the body surface. Exp Physiol 41 (3) 263-270

Weiner JS (1945) The regional distribution of sweating. J Physiol 104: 32-40 
Tables

Table 1.

\begin{tabular}{|c|c|c|c|c|c|c|c|c|c|c|c|c|c|}
\hline & $\mathrm{n}$ & $\begin{array}{l}\text { Age } \\
\text { (yrs) }\end{array}$ & $\begin{array}{l}\text { Height } \\
(\mathrm{cm})\end{array}$ & $\begin{array}{c}\text { Weight } \\
(\mathrm{kg})\end{array}$ & $\begin{array}{c}\text { Surface area } \\
\left(\mathrm{m}^{2}\right)\end{array}$ & $\begin{array}{c}\text { Body Fat } \\
\text { (\%) }\end{array}$ & $\begin{array}{c}\text { Predicted } \\
\mathrm{VO}_{2 \text { max }} \\
\left(\mathrm{ml} \cdot \mathrm{kg}^{-1} \cdot \mathrm{min}^{-1}\right)\end{array}$ & $\begin{array}{l}\text { Av. Total gross } \\
\text { sweat loss based on } \\
\text { mass loss (g) }\end{array}$ & $\begin{array}{c}\text { Av. Total gross } \\
\text { sweat loss based on } \\
\text { mass loss } \\
\left(\mathrm{g} \cdot \mathrm{m}^{-2} \cdot \mathrm{h}^{-1}\right)\end{array}$ & $\begin{array}{c}\text { HR at } 25 \\
\text { min } \\
\text { (bpm) }\end{array}$ & $\begin{array}{c}\text { HR at } 55 \\
\text { min } \\
\text { (bpm) }\end{array}$ & $\begin{array}{l}\text { Av. Treadmill } \\
\text { speed } \\
\text { intensity } 1 \\
\left(\mathrm{~km} \cdot \mathrm{h}^{-1}\right)\end{array}$ & $\begin{array}{l}\text { Av. Treadmill } \\
\text { speed } \\
\text { intensity } 2 \\
\left(\mathrm{~km} \cdot \mathrm{h}^{-1}\right)\end{array}$ \\
\hline WB & 9 & $23 \pm 3$ & $178.5 \pm 4.1$ & $73.8 \pm 5.0$ & $1.92 \pm 0.1$ & $10.9 \pm 4.9$ & $70.2 \pm 13^{*}$ & $1124 \pm 237$ & $473 \pm 103$ & $134 \pm 3$ & $157 \pm 3$ & $10.3 \pm 2.1$ & $13.5 \pm 2.2$ \\
\hline HFN & 9 & $24 \pm 4$ & $181.6 \pm 4.3$ & $73.60 \pm 5.7$ & $1.94 \pm 0.1$ & $11.8 \pm 4.7$ & $57.9 \pm 11$ & $829 \pm 203$ & $365 \pm 86$ & $134 \pm 4$ & $160 \pm 4$ & $8.6 \pm 2.0$ & $11.5 \pm 2.1$ \\
\hline
\end{tabular}


Table 2

\begin{tabular}{|c|c|c|c|c|c|c|c|c|c|c|c|c|c|c|c|c|c|c|c|c|c|c|c|}
\hline & \multirow[b]{3}{*}{$\mathbf{n}$} & \multirow{3}{*}{$\frac{\text { area }}{\mathbf{c m}^{2}}$} & \multicolumn{5}{|c|}{ Absolut sweat data $\left(\mathrm{g} \cdot \mathrm{m}^{-2} \cdot \mathrm{h}^{-1}\right)$} & \multirow[b]{2}{*}{12} & \multirow[b]{3}{*}{$\max$} & \multirow[b]{3}{*}{ median } & \multirow[b]{3}{*}{ mean } & \multirow[b]{3}{*}{ SD } & \multicolumn{3}{|c|}{ Normalised ratio data } & \multirow[b]{3}{*}{ IQR } & \multirow{2}{*}{\multicolumn{2}{|c|}{\begin{tabular}{|l|} 
Pearson's r \\
GSL and RSR \\
\end{tabular}}} & \multirow{2}{*}{\multicolumn{2}{|c|}{$\begin{array}{l}\text { Significance level of } \\
\text { intensity comparison }\end{array}$}} & \multicolumn{3}{|c|}{ Sudomotor sensitivity } \\
\hline & & & I1 & & & & & & & & & & \multicolumn{2}{|l|}{ I1 } & \multirow{2}{*}{$\begin{array}{l}\text { I2 } \\
\text { Median }\end{array}$} & & & & & & $\left(\right.$ g. $\mathrm{m}^{-2}$ & $\left.{ }^{2} \cdot{ }^{\circ} \mathrm{C}^{-1}\right)$ & $\left(\mathbf{m g} \cdot \mathrm{cm}^{-2} \cdot \mathrm{min}^{-1} \cdot{ }^{\circ} \mathrm{C}^{-1}\right)$ \\
\hline & & & $\min$ & $\max$ & median & mean & SD & $\min$ & & & & & Median & IQR & & & I1 & \begin{tabular}{l|l} 
I2 \\
\end{tabular} & $\begin{array}{c}\text { Absolute } \\
\text { data }\end{array}$ & $\begin{array}{c}\text { Normalised } \\
\text { ratio data }\end{array}$ & I1 & I2 & \begin{tabular}{|l|} 
Overall \\
\end{tabular} \\
\hline shoulders & 9 & 689 & 214 & 533 & 267 & 322 & 109 & 382 & 915 & 656 & 620 & 202 & 1.07 & 0.51 & 1.67 & 0.38 & 0.57 & 0.78 & $* * * \# \#$ & $* *$ & 385 & 1089 & 0.98 \\
\hline lat upper chest & 9 & 366 & 114 & 496 & 262 & 257 & 110 & 267 & 951 & 498 & 485 & 201 & 1.05 & 0.58 & 1.27 & 0.76 & 0.27 & 0.24 & 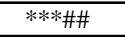 & $* * \$$ & 378 & 662 & 0.77 \\
\hline centre upper chest & 9 & 370 & 134 & 593 & 318 & 324 & 148 & 301 & 1058 & 546 & 606 & 262 & 1.28 & 0.50 & 1.39 & 0.67 & 0.53 & 0.59 & ***\#\# & $* * \$$ & 458 & 639 & 0.96 \\
\hline lat mid chest & 9 & 372 & 191 & 433 & 244 & 274 & 80 & 214 & 744 & 390 & 438 & 164 & 0.98 & 0.20 & 0.99 & 0.33 & 0.63 & 0.51 & $* * \$$ & - & 351 & 409 & 0.69 \\
\hline centre mid chest & 9 & 186 & 159 & 742 & 370 & 383 & 170 & 241 & 1077 & 584 & 658 & 267 & 1.49 & 0.74 & 1.49 & 0.82 & 0.59 & 0.55 & $* * \$$ & - & 534 & 598 & 1.04 \\
\hline sides & 9 & 390 & 97 & 498 & 230 & 247 & 118 & 210 & 681 & 364 & 448 & 183 & 0.93 & 0.40 & 0.93 & 0.36 & 0.54 & 0.81 & $* * \$$ & * & 332 & 374 & 0.71 \\
\hline lower chest & 9 & 171 & 46 & 365 & 174 & 186 & 86 & 157 & 621 & 381 & 401 & 164 & 0.70 & 0.49 & 0.97 & 0.59 & 0.20 & 0.55 & $* * \$$ & * & 251 & 581 & 0.64 \\
\hline lat upper back & 9 & 425 & 332 & 875 & 515 & 554 & 190 & 535 & 1296 & 840 & 831 & 251 & 2.07 & 0.43 & 2.14 & 0.25 & 0.91 & 0.93 & $* * * \#$ & - & 742 & 912 & 1.32 \\
\hline centre upper back & 9 & 235 & 384 & 1036 & 707 & 710 & 246 & 530 & 1476 & 1197 & 1062 & 360 & 2.84 & 0.46 & 3.05 & 0.75 & 0.88 & 0.77 & $* * * \# \#$ & - & 1019 & 1374 & 1.68 \\
\hline lat M-U back & 9 & 203 & 136 & 629 & 431 & 398 & 162 & 304 & 893 & 750 & 630 & 212 & 1.73 & 0.39 & 1.91 & 0.31 & 0.83 & 0.79 & ***\#\# & - & 621 & 895 & 1.00 \\
\hline lat M-L back & 9 & 191 & 216 & 708 & 322 & 370 & 160 & 281 & 961 & 742 & 653 & 243 & 1.29 & 0.45 & 1.89 & 1.05 & 0.71 & 0.55 & $* * \$$ & - & 464 & 1178 & 1.04 \\
\hline centre mid back & 9 & 195 & 484 & 1288 & 771 & 797 & 250 & 689 & 1674 & 1147 & 1139 & 364 & 3.10 & 0.59 & 2.93 & 0.79 & 0.45 & 0.30 & $* *$ & - & 1111 & 1056 & 1.81 \\
\hline lower back & 9 & 167 & 294 & 1751 & 677 & 744 & 434 & 390 & 2094 & 856 & 970 & 515 & 2.72 & 0.95 & 2.18 & 0.42 & 0.51 & 0.82 & - & - & 975 & 501 & 1.54 \\
\hline ant upper leg & 9 & 736 & 150 & 453 & 271 & 280 & 103 & 259 & 607 & 370 & 390 & 128 & 1.09 & 0.14 & 0.94 & 0.09 & 0.82 & 0.80 & ***\#\# & - & 390 & 279 & 0.62 \\
\hline med upper leg & 9 & 735 & 104 & 386 & 166 & 202 & 91 & 157 & 532 & 237 & 278 & 117 & 0.67 & 0.21 & 0.60 & 0.23 & 0.94 & 0.86 & $* * \$$ & - & 2 & 197 & 0.44 \\
\hline pos upper leg & 9 & 736 & 133 & 316 & 200 & 209 & 56 & 174 & 397 & 244 & 274 & 79 & 0.80 & 0.13 & 0.62 & 0.22 & 0.88 & 0.72 & *** & - & 288 & 122 & 0.43 \\
\hline lat upper leg & 9 & 739 & 150 & 576 & 276 & 325 & 146 & 139 & 729 & 388 & 405 & 168 & 1.11 & 0.17 & 0.99 & 0.24 & 0.87 & 0.83 & $* *$ & * & 398 & 313 & 0.64 \\
\hline ant lat lower leg & 9 & 553 & 160 & 676 & 270 & 355 & 210 & 259 & 927 & 332 & 441 & 218 & 1.09 & 0.60 & 0.85 & 0.26 & 0.86 & 0.81 & $*$ & - & 390 & 172 & 0.70 \\
\hline ant med lower leg & 9 & 557 & 177 & 818 & 351 & 415 & 231 & 296 & 986 & 461 & 515 & 221 & 1.41 & 0.43 & 1.18 & 0.40 & 0.91 & 0.85 & $* *$ & - & 506 & 307 & 0.82 \\
\hline pos lower leg & 9 & 1025 & 144 & 475 & 211 & 256 & 105 & 197 & 623 & 304 & 338 & 133 & 0.85 & 0.21 & 0.78 & 0.19 & 0.91 & 0.86 & $* * \$$ & - & 304 & 261 & 0.54 \\
\hline ant upper arm & 9 & 730 & 65 & 320 & 136 & 145 & 81 & 143 & 463 & 257 & 258 & 90 & 0.55 & 0.26 & 0.65 & 0.19 & 0.87 & 0.81 & ***\#\# & $* *$ & 196 & 339 & 0.41 \\
\hline pos upper arm & 9 & 738 & 32 & 370 & 123 & 148 & 109 & 104 & 521 & 230 & 259 & 118 & 0.49 & 0.25 & 0.59 & 0.23 & 0.83 & 0.80 & ***\#\# & $* *$ & 177 & 301 & 0.41 \\
\hline ant lower arm & 9 & 644 & 106 & 494 & 226 & 238 & 140 & 247 & 487 & 372 & 359 & 80 & 0.91 & 0.47 & 0.95 & 0.14 & 0.90 & 0.72 & $* *$ & - & 325 & 411 & 0.57 \\
\hline pos lower arm & 9 & 640 & 106 & 571 & 221 & 255 & 161 & 221 & 644 & 399 & 393 & 132 & 0.89 & 0.34 & 1.02 & 0.17 & 0.91 & 0.83 & $* * \$$ & - & 318 & 498 & 0.62 \\
\hline thumbs & 9 & 126 & 86 & 332 & 136 & 185 & 94 & 134 & 370 & 254 & 244 & 85 & 0.55 & 0.28 & 0.65 & 0.32 & 0.49 & 0.37 & $* *$ & - & 196 & 330 & 0.39 \\
\hline fingers & 9 & 468 & 57 & 235 & 86 & 118 & 68 & 77 & 232 & 144 & 153 & 51 & 0.34 & 0.19 & 0.37 & 0.10 & 0.49 & 0.45 & $* *$ & - & 123 & 163 & 0.24 \\
\hline palms & 9 & 339 & 39 & 191 & 86 & 98 & 58 & 60 & 226 & 119 & 126 & 53 & 0.35 & 0.28 & 0.30 & 0.20 & 0.58 & 0.40 & $* *$ & - & 124 & 93 & 0.20 \\
\hline dorsal hand & 9 & 407 & 72 & 340 & 126 & 165 & 93 & 140 & 319 & 251 & 235 & 72 & 0.51 & 0.33 & 0.64 & 0.23 & 0.77 & 0.33 & $*$ & - & 182 & 350 & 0.37 \\
\hline gluts & 9 & 398 & 99 & 471 & 261 & 267 & 131 & 198 & 617 & 353 & 365 & 130 & 1.05 & 0.43 & 0.90 & 0.21 & 0.48 & 0.72 & * & - & 376 & 258 & 0.58 \\
\hline sole & 9 & 192 & 83 & 362 & 167 & 202 & 95 & 122 & 367 & 219 & 225 & 84 & 0.67 & 0.16 & 0.56 & 0.05 & 0.56 & 0.35 & - & $* * \$$ & 241 & 145 & 0.36 \\
\hline dorsal foot & 9 & 580 & 112 & 575 & 202 & 274 & 158 & 152 & 583 & 298 & 316 & 145 & 0.81 & 0.31 & 0.76 & 0.28 & 0.46 & 0.36 & - & - & 291 & 270 & 0.50 \\
\hline toes & 9 & 115 & 85 & 250 & 149 & 163 & 52 & 104 & 240 & 179 & 174 & 42 & 0.60 & 0.34 & 0.46 & 0.12 & 0.30 & 0.20 & - & $* *$ & 215 & 83 & 0.28 \\
\hline heel & 9 & 92 & 90 & 267 & 151 & 166 & 58 & 145 & 284 & 155 & 179 & 52 & 0.61 & 0.38 & 0.40 & 0.21 & 0.19 & 0.01 & - & $* * \$$ & 218 & 11 & 0.28 \\
\hline med ankles & 9 & 184 & 159 & 837 & 363 & 429 & 259 & 145 & 867 & 390 & 445 & 246 & 1.46 & 0.70 & 1.00 & 0.47 & 0.58 & 0.41 & - & $*$ & 524 & 75 & 0.71 \\
\hline lat ankles & 9 & 167 & 73 & 813 & 193 & 272 & 235 & 103 & 465 & 290 & 249 & 125 & 0.78 & 0.20 & 0.74 & 0.31 & 0.20 & 0.51 & - & - & 279 & 270 & 0.39 \\
\hline forehead & $\begin{array}{l}9 \\
\end{array}$ & $\begin{array}{l}56 \\
\end{array}$ & 188 & 1882 & 697 & 894 & 708 & 923 & 3262 & 1710 & 2057 & 9000 & 2.61 & 5.33 & 2.60 & 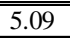 & 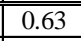 & 0.56 & 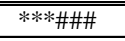 & & 1174 & 3187 & 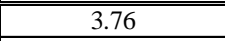 \\
\hline chin & 9 & 23 & 0 & 222 & 130 & 126 & 76 & 208 & 606 & 302 & 351 & 149 & 0.49 & 0.86 & 0.46 & 0.45 & 0.19 & 0.17 & $* * \#$ & & 220 & 539 & 0.64 \\
\hline cheeks & 9 & 128 & 33 & 440 & 85 & 139 & 128 & 206 & 1224 & 279 & 398 & 318 & 0.32 & 0.77 & 0.42 & 0.41 & 0.40 & 0.17 & $* * \$$ & & 143 & 611 & 0.73 \\
\hline neck & 9 & 322 & 19 & 407 & 288 & 245 & 137 & 91 & 1026 & 622 & 593 & 275 & 1.08 & 1.29 & 0.94 & 1.28 & 0.68 & 0.47 & $* * \#$ & & 486 & 1049 & 1.09 \\
\hline medial head & 4 & 308 & 28 & 650 & 170 & 255 & 285 & 249 & 881 & 536 & 551 & 259 & 0.64 & 0.20 & 0.81 & 0.12 & 0.38 & 0.11 & - & & 287 & 1151 & 1.01 \\
\hline r. lat head & 4 & 231 & 38 & 919 & 337 & 407 & 396 & 430 & 1368 & 799 & 849 & 433 & 1.26 & 0.38 & 1.21 & 0.29 & 0.49 & 0.31 & $* * \#$ & & 567 & 1456 & 1.55 \\
\hline l.lat head & 4 & 231 & 48 & 494 & 304 & 288 & 232 & 421 & 1177 & 723 & 761 & 358 & 1.14 & 0.17 & 1.10 & 0.08 & 0.62 & 0.45 & $*$ & & 512 & 1317 & 1.39 \\
\hline
\end{tabular}




\section{Legends}

Table 1. Participant characteristics (mean \pm SD) of whole body (WB) and head, face, and neck (HFN) sweat mapping, gross sweat loss, heart rate (HR) and running speed during the experimental protocol.

Table 2. Descriptive statistics for all regions sampled at I1 and I2 and statistical comparison of sweat rates within each region between exercise intensities for both absolute and normalised data, corrected and uncorrected for multiple comparisons. $\mathrm{n}=$ number of participants. Grey shading in columns for normalised ratio data indicates significant deviation from 1, i.e. average sweat rate. A decrease in median sweat rate ratio between intensities is indicated by grey shading in the intensity comparison column $(\square)$. Sudomotor sensitivity for all regions tested, calculated as changes in regional sweat rate divided by change in Tcore ( $\Delta$ Tcore), for both intensities and overall (Taylor et al. 2006). For conversion of absolute sweat rates (in g.m $\mathrm{m}^{-2} \cdot \mathrm{h}^{-1}$ ) to other units: divide by 600 to get $\mathrm{mg} \cdot \mathrm{cm}^{-2} \cdot \mathrm{min}^{-1}$, or by 10,000 to get $\mathrm{ml} . \mathrm{cm}^{-2} \cdot \mathrm{h}^{-1}$. Level of significance with no correction for multiple comparisons: ${ }^{*} \mathrm{p}<0.05$, ${ }^{* *} \mathrm{p}<0.01,{ }^{* * *} \mathrm{p}<0.001$. Level of significance following Bonferroni correction: \# $\mathrm{p}<0.05$, \#\# $\mathrm{p}<0.05, \# \# \mathrm{p}<0.0001, \$ 0.1>\mathrm{p}>0.05$. 
Figure 1. Absolute mean GSL $\left(\mathrm{g} \cdot \mathrm{h}^{-1}\right)$ and absolute mean metabolic rate (W) for combined WB and HFN participants at exercise intensity 1 (I1) and intensity 2 (I2).

Figure 2. Absolute regional median sweat rates of male athletes at exercise intensity 1 . Note: head data were obtained from a partially different subject group. Data were corrected for inter-group differences (refer to text).

Figure 3. Absolute regional median sweat rates of male athletes at exercise intensity 2. Note: head data were obtained from a partially different subject group. Data were corrected for inter-group differences (refer to text).

Figure 4. Normalized regional median sweat rates of male athletes at exercise intensity 1. Note: head data were obtained from a partially different subject group. Data were corrected for inter-group differences (refer to text).

Figure 5. Normalized regional median sweat rates of male athletes at exercise intensity 2. Note: head data were obtained from a partially different subject group. Data were corrected for inter-group differences (refer to text). 


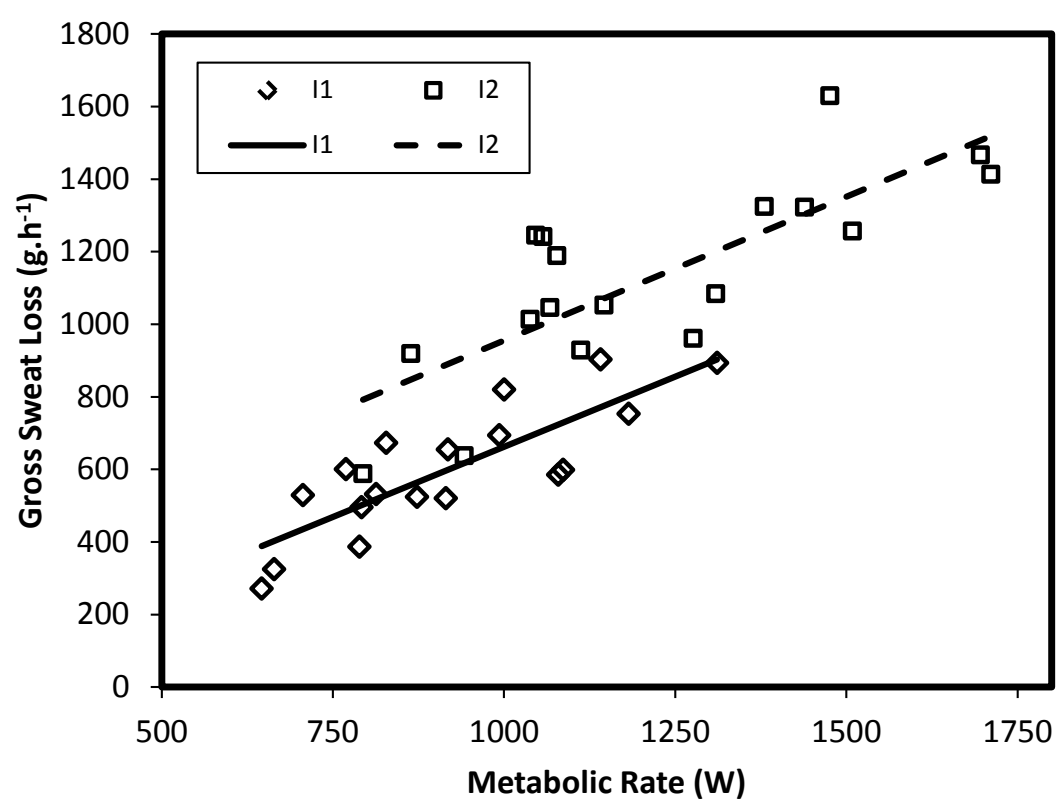

Fig 1 

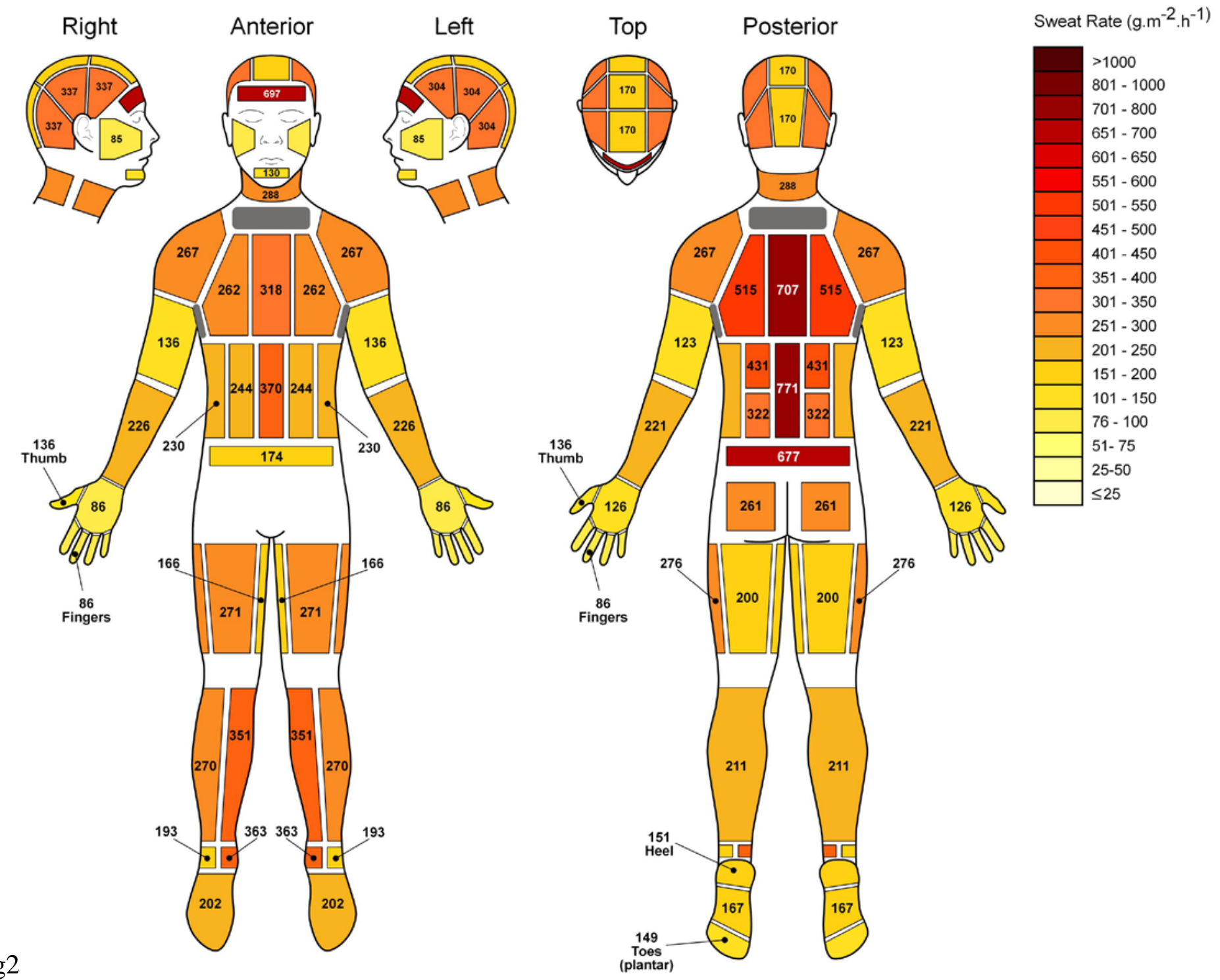


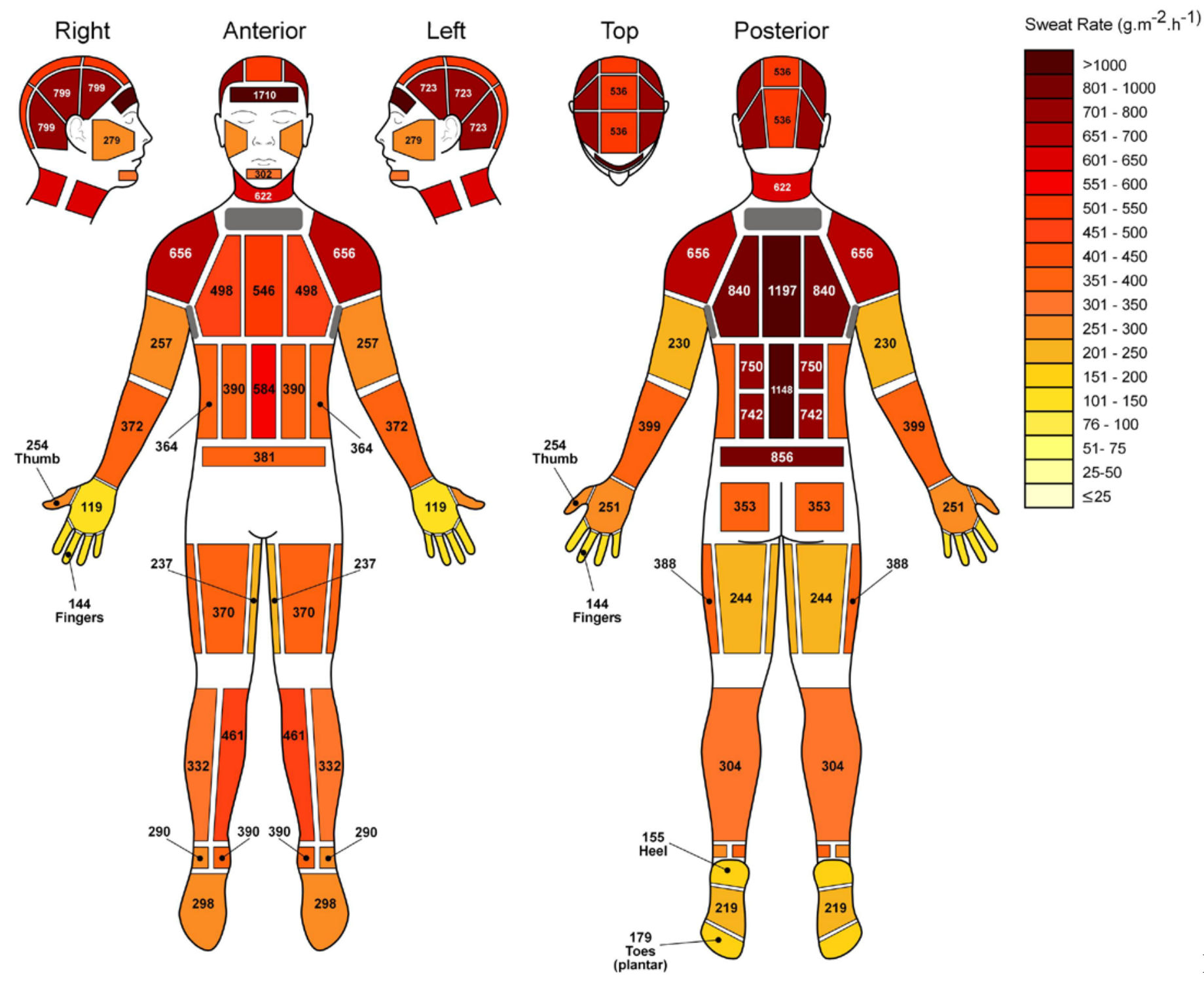



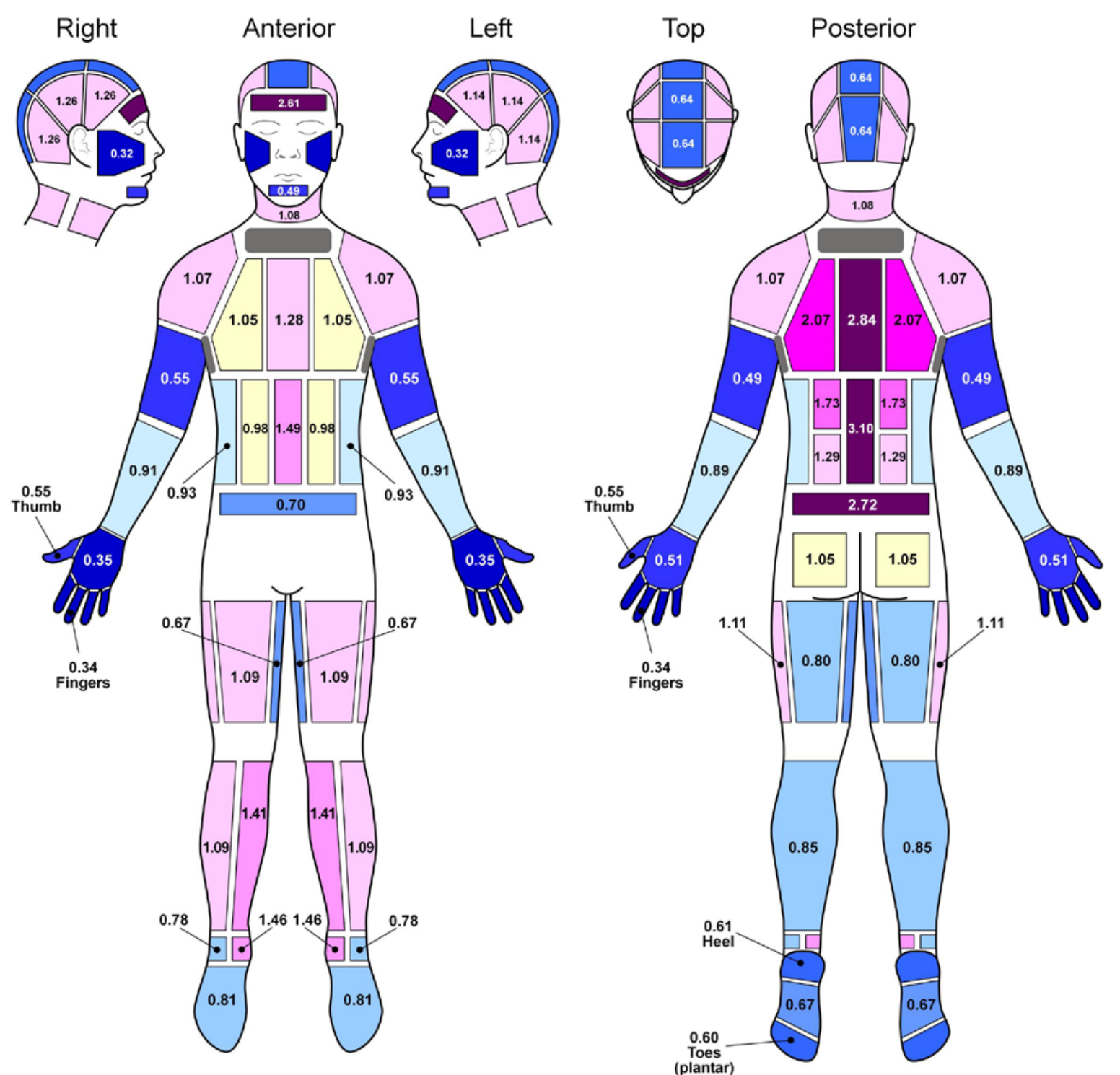

Ratio Values

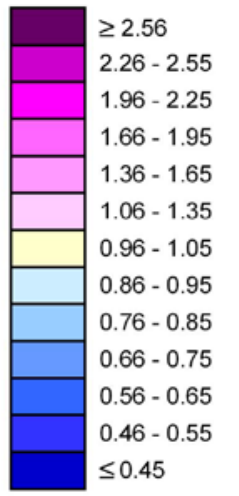

Ratios calculated using area

$>1=$ higher than gross sweat loss eat loss $<1=$ less than gross sweat loss

(poes 

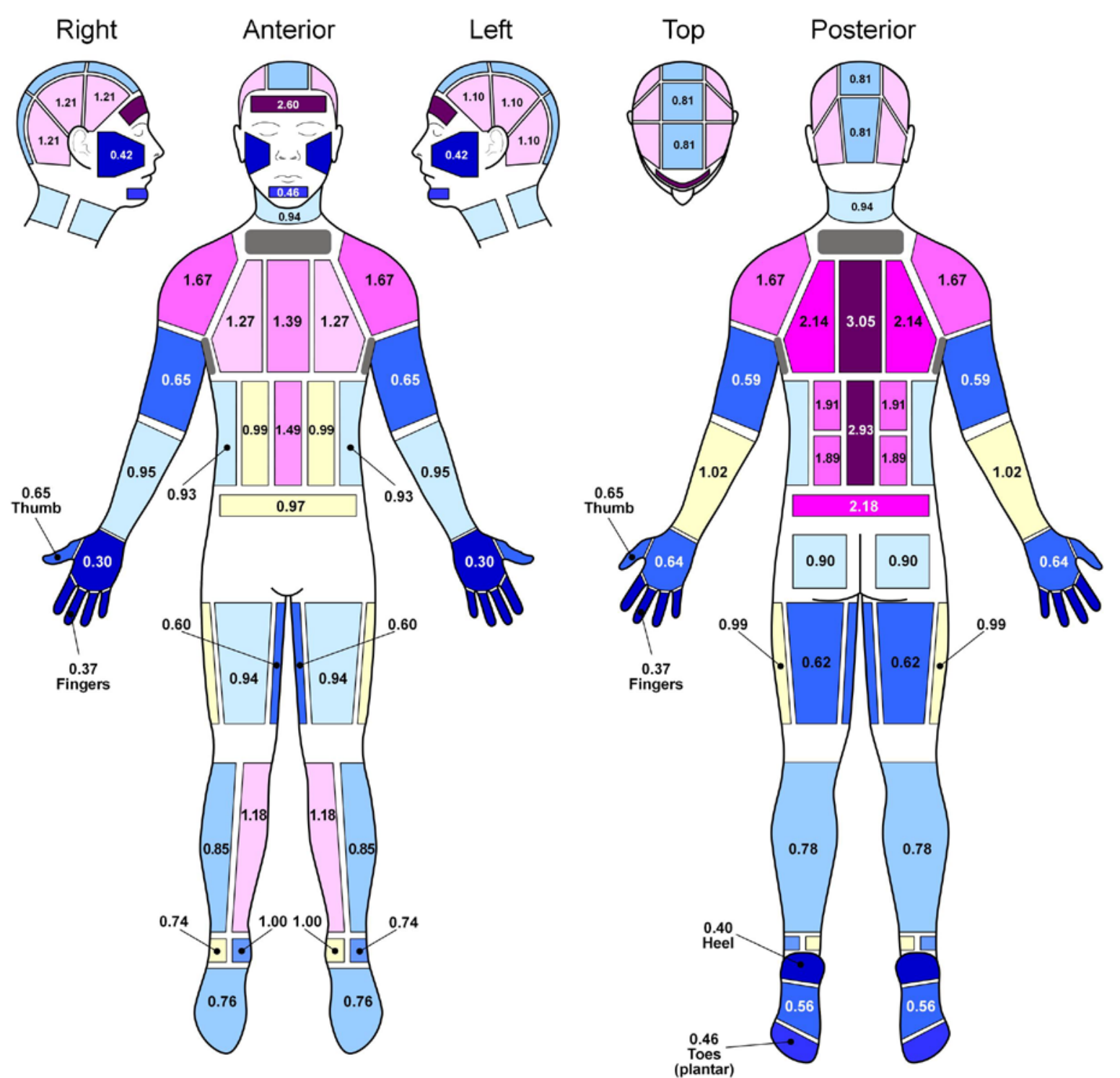

Ratio Values

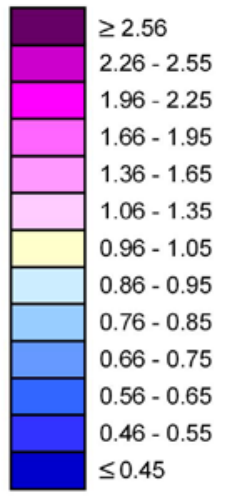

Ratios calculated using area

$>1=$ higher than gross sweat loss $\begin{aligned} 1 & =\text { gross sweat loss } \\ <1 & =\text { less than gross sweat loss }\end{aligned}$

(plantar) 